\title{
Iraqi JMS
}

Published by Al-Nahrain College of Medicine ISSN 1681-6579

Email: iraqijms@colmed-alnahrain.edu.iq http://www.colmed-alnahrain.edu.iq http://www.iraqijms.net

\section{New Human Body Parts Discovered}

\author{
Hayder J. Mubarak $P h D$ \\ Dept. of Human Anatomy, College of Medicine, Al-Nahrain University, Iraq
}

\begin{abstract}
Reports about new discoveries in human anatomy could help in the progress of medical care in term of diagnosis and management. Among the many of these was the hidden system of vessels discovered in the human brain in 2015 , the anterolateral ligament of the knee joint describe in 2013, Dua's layer discovered in the human cornea in 2013, and the description of the anatomic structure of the G-spot done in 2012. These new part of the human body may be more properly considered as newly discovered variations in the human body.
\end{abstract}

Keywords: Anatomy, human discoveries, brain lymphatics, knee joint, Dua's layer, G-spot.

\section{Introduction}

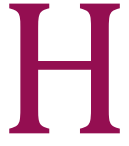

uman anatomy had been studied in details since hundreds of years; physicians always thought that they know everything about human anatomy. However, the reports of new discoveries in human anatomy proved that there is always something more to learn that could help patients and doctors ${ }^{(1)}$. The knowledge of newly discovered human morphology is important to improve diagnostic and interventional performance for imaging techniques such as echocardiography, magnetic resonance imaging, computerized tomography, endoscopy; open and laparoscopic surgery ${ }^{(2)}$.

This article presents 4 of the most recent anatomical discoveries, their regional variation provoked interest to encourage anatomists and clinicians to be aware of the existence of other new human body parts.

\section{Lymphatic vessels of the human brain}

The most recent of these new human body part discovered at the University of Virginia in (2015) was a hidden system of vessels discovered in the human brain, which drain lymphatic fluid from the brain to the surrounding lymph nodes. After this new discovery, neuroimmunologists are trying to investigate the mechanisms of brain drainage and inflammation, and a new map of lymphatics was drawn. This newly discovered lymphatic vessels in the brain were found in the dural sinuses draining blood from the internal and external veins of the brain into the internal jugular veins, their locations were nearer to the major blood vessel ${ }^{(3)}$.

Before that discovery, the central nervous system was considered to lack lymphatic vasculature, which has raised long-standing questions about how cerebral interstitial fluid is cleared of waste products ${ }^{(4)}$. After centuries, it was presumed that the lymphatic system simply didn't extend to the brain. The discovery of hidden system of lymphatic vessels in the human brain may help in understanding and treating many disorders, including multiple sclerosis, Alzheimer's disease, and Parkinson's disease. New plans are now established to investigate variables aspects of this issue ${ }^{(5)}$.

\section{Anterolateral ligaments of the knee joint}


Another new human body part discovered at the University Hospitals Leuven in Belgium in (2013) was a ligament in the knee, which appears to play a role in patients suffering from a tear in their anterior cruciate ligament. This ligament was described as the anterolateral ligament, it was found in $97 \%$ of all cases. The presence of this ligament was hypothetized in 1879 as an unknown ligament in the knee. Patients who had undergone repairs to their anterior cruciate ligament were experienced trouble with the knee giving way mid-motion even after the surgical recovery appeared to be complete. Patients whose knees remained unstable, a condition known as "pivot shift," were found to have damage in the anterolateral ligament. It was suggested that the close association of the femoral origins of the fibular collateral ligament and anterolateral ligament allowed referral to both these ligaments as one structure, the lateral collateral ligament complex. The anatomic location of the anterolateral ligament suggested that the structure of this ligament may be an important stabilizer for internal rotation ${ }^{(6)}$.

The anterolateral ligament arises from the lateral femoral epicondyle, proximal and posterior to the popliteus tendon, and with posterior fibers blending with the proximal fibular collateral ligament. The anterolateral ligament has a strong connection with the periphery of the body of the lateral meniscus by way of its meniscofemoral and meniscotibial components. Distally, the ligament inserts adjacent to head of fibula, with distal flaring clearly apparent. There is no connection of the ligament with the lateral capsule proximally or with the iliotibial band distally ${ }^{(7)}$.

\section{Dua's layer of the human cornea}

Histological new discovery at the University of Nottingham in England in (2013) was a strong, impervious to air layer of 15 microns thickness in human cornea. This microscopic layer had been called as Dua's layer following the name of the scientist discovered it. It was seen at the back of the cornea between the corneal stroma and Descemet's membrane, and it was considered as the sixth layer of the cornea. Prior to this discovery, the cornea was believed to have only five layers (from the outside in); the corneal epithelium, Bowman's layer, the corneal stroma, Descemet's membrane, and the corneal endothelium ${ }^{(8)}$.

It was confirmed that the tear in Dua's layer of the cornea is the cause of corneal hydrops (a disorder that leads to fluid buildup in the cornea). The discovery of Dua's layer makes the eye surgery safer and simple; it could dramatically improve outcomes of corneal grafts and transplants. Eye surgeons taking advantage of Dua's layer by injecting air bubbles needed during some surgeries under the layer rather than above it, where there is a chance of air causing damage to the corneal stroma ${ }^{(9)}$.

\section{Anatomical structure of G-spot:}

The anatomic structure of the G-spot has not been documented till 2012, at that year, the Gspot had been distinguished as an anatomic structure that is located on the dorsal perineal membrane, $16.5 \mathrm{~mm}$ from the upper part of the urethral meatus, and creates a $35^{\circ}$ angle with the lateral border of the urethra. The lower pole (tail) and the upper pole (head) were located 3 and $15 \mathrm{~mm}$ next to the lateral border of the urethra, respectively. Grossly, the G-spot was described as a well-delineated sac with walls that resembled fibroconnective tissues and resembled erectile tissues. The superior surface of the sac had bluish irregularities visible through the coat. Upon opening the sac's upper coat, blue grape-like anatomic compositions of the G-spot emerged with dimensions of length (L) of $8.1 \mathrm{~mm} \times$ width (W) of 3.6-1.5 $\mathrm{mm} \times$ height (H) of $0.4 \mathrm{~mm}$. The $\mathrm{G}$-spot structure had three distinct areas: the proximal part (the head) $L 3.4$ $\mathrm{mm} \times \mathrm{W} 3.6 \mathrm{~mm}$, the middle part $\mathrm{L} 3.1 \mathrm{~mm} \times \mathrm{W}$ $3.3 \mathrm{~mm}$, and the distal part (tail) $\mathrm{L} 3.3 \mathrm{~mm} \times \mathrm{W}$ $3.0 \mathrm{~mm}$. From the distal tail, a rope-like structure emerged, which was seen for approximately 1.6 
$\mathrm{mm}$ and then disappeared into the surrounding tissue ${ }^{(10)}$.

Finally, the question now, are these discovered human body parts new?

The answer to this question should probably considere that the body is formed of complex structures, with extraordinary variations seen in some individuals ${ }^{(11)}$. One example: An arm muscle known as the palmaris longus simply is absent in $16 \%$ of the population ${ }^{(12)}$. Other example: The plantaris muscle of the leg is absent in about $14 \%$ of people ${ }^{(13)}$. These new part of the human body may be more properly considered as newly discovered variations in the human body.

Anatomical variations may influence predisposition to diseases, symptomatology, clinical examination, investigation and patient management including operative surgery ${ }^{(14)}$. Indeed, there are reports that a substantial proportion of clinical malpractice may be attributed to ignorance of anatomical variations. This realization has informed inclusion of anatomical variations among the aims to be considered in medical curricula ${ }^{(15)}$.

It is of significantly important not to consider that human already had a complete "map" of the human body. The history of human anatomy was always witness new discoveries.

The human anatomy departments should not be closed, and the fact that medical students today learn about the human body only from books and computer simulations is a bad sign concerning medical progress.

\section{References}

1. Michael B. The Aanatomical enlightenment. Austin J Surg. 2015; 2(1): 1-6.

2. Jones DG, Dias GJ, Mercer S, et al. Clinical anatomy research in a research driven anatomy department. Clin Anat. 2002; 15(3): 228-32.
3. Antoine L, Igor S, Timothy JK, et al. Structural and functional features of central nervous system lymphatic vessels. Nature. 2015; 523, 337-41.

4. Iliff JJ, Nedergaard M. The microcirculation-fantastic voyage: Is there a cerebral lymphatic system? Stroke. 2013; 44: 93-5.

5. Lasse DO, Soyon $\mathrm{H}$, Beth $\mathrm{S}$. New brain lymphatic vessels drain old concepts. EbioMedicine. 2015; 2: 776-7.

6. Claes S, Vereecke E, Maes M, et al. Anatomy of the anterolateral ligament of the knee. J Anat. 2013; 223: 321-8.

7. Jack $P$, Ezekiel $M$, Michael $R$, et al. The anterolateral ligament of the knee: MRI appearance, association with the segond fracture, and historical perspective. 2015; 204 (2): 367-73.

8. Dua HS, Lana A. Dua's Layer: its discovery, characteristics and applications. J Emmetropia. 2014; 5: 211-23.

9. Dua HS, Faraj LA, Said DG, Gray T. Human corneal anatomy redefined: a novel pre-Descemet's layer (Dua's layer). Ophthalmology. 2013; 120(9): 1778-85.

10. Ostrzenski A. G-spot anatomy: a new discovery. J Sex Med. 2012; 9(5): 1355-9.

11. Julius $O$. Clinical significance of anatomical variations. Anatomy Journal of Africa. 2013; 2 (1): 57-60.

12. Thompson NW, Mockford BJ, and Cran GW. Absence of the palmaris longus muscle: a population study. Ulster Med J. 2001; 70(1): 22-4.

13. Ozkan K, Tolga E, Bahtiyar D, et al. Prediction of the presence of plantaris tendon through examination of palmaris longus tendon. Is there a link? Int J Morphol. 2014; 32(2): 589-92.

14. Willan PL, Humpherson JR. Concepts of Variation and normality in morphology: important issues at risk of neglect in modern undergraduate medical courses. Clin Anat. 1999; 12: 186-90.

15. Sanudo JR, Vazquez R, Puerta J. Meaning and Clinical Interest of the anatomical Variations in the $21^{\text {st }}$ Century. Eur J Anat. 2003; 7: 1-3.

\section{E-mail: hayder_67_67@yahoo.com Received 15 ${ }^{\text {th }}$ Aug.2016: Accepted $22^{\text {nd }}$ Aug.2016}

